\title{
Children's Motivations for Video Game Play in the Context of Normal Development
}

\author{
Cheryl K. Olson \\ Massachusetts General Hospital
}

\begin{abstract}
Electronic games are now an everyday part of childhood and adolescence. The debate has moved from whether children should play video games to how to maximize potential benefits and to identify and minimize potential harms. To do this, we must understand what motivates children to play electronic games and what needs the games meet. Drawing on a survey of 1,254 middle school children, focus groups with boys and their parents, and findings from other quantitative and qualitative research, the author describes a variety of motivations for video game play (including games with violent content) and how these may vary based on factors such as mood, environment, personality, and developmental stage. The findings are put into the context of normal development, and suggestions are given for parents, educators, and researchers.
\end{abstract}

Keywords: video games, child development, adolescence, motivation

A number of studies indicate that electronic games are now a routine part of normal childhood and adolescence (e.g., Greenberg, Sherry, Lachlan, Lucas, \& Holmstrom, 2008; Ito et al., 2008; Lenhart et al., 2008; Olson et al., 2007; Roberts, Foehr, \& Rideout, 2005). Until recently, most studies on video games have focused on potential harms to children from exposure to inappropriate game content. Some researchers are now exploring what children can gain from electronic games, often emphasizing their potential to teach academic skills. The potential benefits and uses of electronic games are best understood in the context of children's motivations for play. Parents choosing appropriate leisure-time games, educators seeking games to supplement classroom teaching, game developers creating games to teach, and mental health professionals using games in clinical situations all need to know what is likely to engage a child and what emotional or developmental needs a young person may (consciously or not) seek to address through games (von Salisch, Oppl, \& Kristen, 2006). This article reviews research and ideas that may advance this understanding.

I also draw on survey data collected from 1,254 students attending Grades 7 and 8 (>98\% 12 to 14 years of age) in public schools in South Carolina and Pennsylvania (Olson et al., 2007) concerning patterns of media use and self-reported reasons for playing electronic games. Children responded to 17 possible motivations for playing electronic games on a 4-point scale from strongly disagree to strongly agree. A write-in option was included, but drew few responses. (In the survey, electronic games were defined as computer, video, or handheld games. In this article, I use the common term video games to refer to all of these.)

This research was supported by Grant 2003-JN-FX-0078 awarded by the Office of Juvenile Justice and Delinquency Prevention, Office of Justice Programs, U.S. Department of Justice.

Correspondence concerning this article should be addressed to Cheryl K. Olson, Center for Mental Health and Media, Massachusetts General Hospital, Department of Psychiatry, Wang 812, 15 Parkman Street, Boston, MA 02114. E-mail: colson@hms.harvard.edu
Figure 1 displays the percentages of boys and girls who strongly agreed with each reason. The only reason selected more often by girls than boys was, "It's something to do when I'm bored," although the difference was not statistically significant. Boys were significantly more likely than girls to play for fun, to compete with other people and to win, for the challenge of figuring the game out, and for several emotional reasons (excitement, relaxation, and coping with anger). This was also true for liking to "mod" games (defined as changing the game using computer code), playing because friends like to play, and enjoying "the guns and other weapons." Roughly equal proportions of boys and girls were strongly motivated by creativity ("I like to create my own world") and curiosity ("I like to learn new things").

\section{Social Motivations for Video Game Play}

\section{A Focus for Hanging Out}

Many adults view video game play as an isolating activity. They picture a child playing alone in a room or basement. The children we studied saw video games as intensely social. At the most basic level, video games provide a rationale for hanging out and structuring time spent with friends. In some ways, this is an evolution of the role played by board games or activities such as bowling (Ito \& Bittani, 2009). Video games are also a focus for casual conversation. In focus groups (Olson, Kutner, \& Warner, 2008), young adolescent boys said games were a frequent focus for conversation among their peers, for example, "If I didn't play video games-it's kind of a topic of conversation, and so I don't know what I'd talk about. 'Cause I talk about video games a lot." Asked what kids at his school would talk about if they were not talking about games, another boy replied, "I don't know. Probably like girls, or something like that .... I don't even know, 'cause the most they talk about is girls and games-the two Gs."

\section{The Joy of Competition}

In our survey of 1,254 students (Olson et al., 2007), the chance to compete and win was one of the strongest motivators for video 


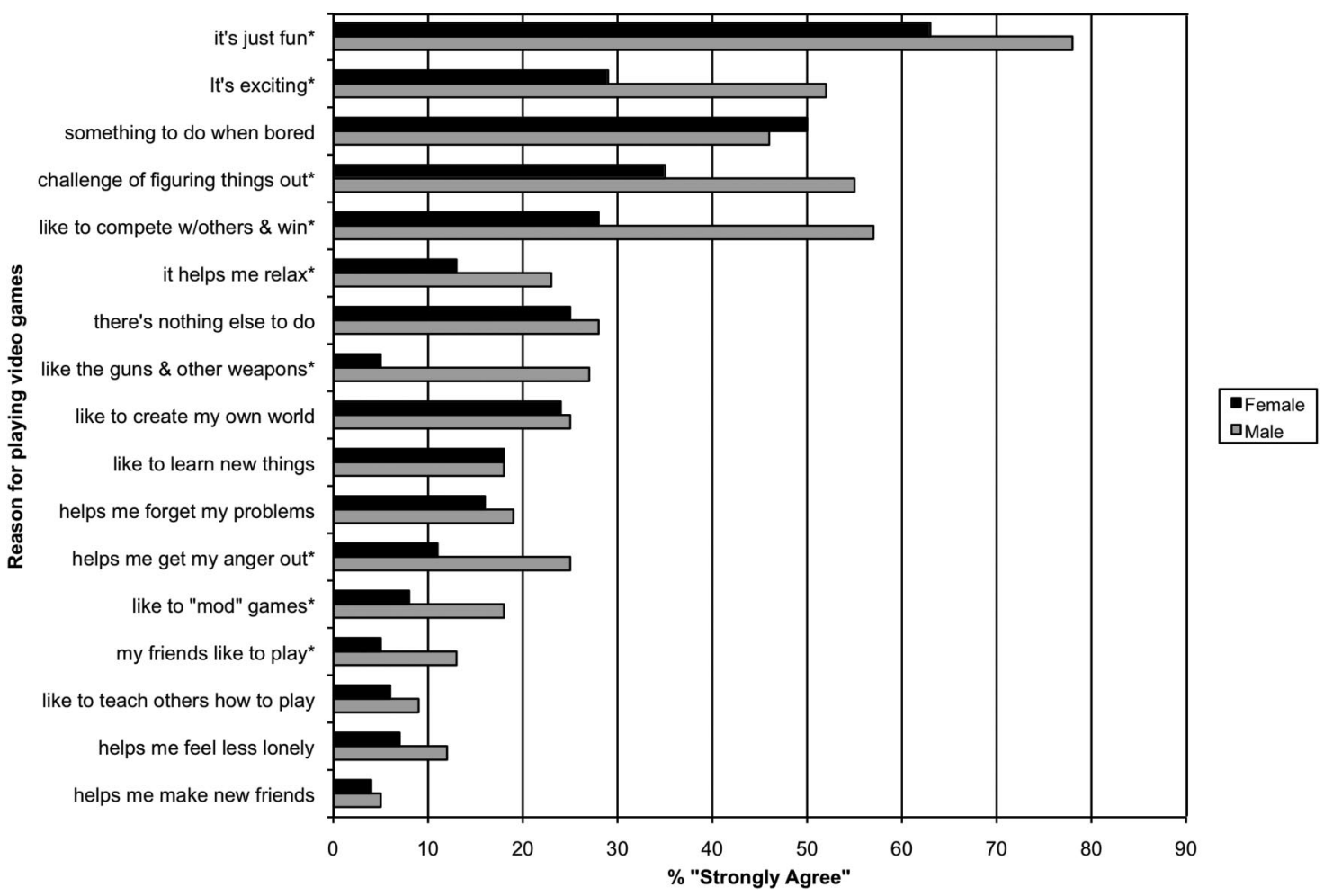

Figure 1. "I play electronic games because...." Reasons for playing video games for boys and girls. Agreement percentages for questions followed by asterisk (*) significantly larger for boys at $p<.001$ by Fisher's exact test $(n=1,137)$.

game play among boys. More than four of five boys surveyed indicated that they were motivated by competition, and $57 \%$ strongly agreed. The theme of competition also arose in nearly every focus group we conducted with young adolescent boys (Olson et al., 2008). For example, when a researcher asked one boy what part of a game was his favorite, he responded, "Beating people!"

These results are in line with a qualitative study by the British Board of Film Classification (BBFC; Cragg, Taylor, \& Toombs, 2007), in which boys talked about competing and the bragging rights that come with winning. The report noted that men were more likely than women to play video games in groups, and that "the social rewards of gaming - talking about how you are doing, playing together, helping or beating each other-are less a part of the attraction for females than males" (p. 31). However, over half $(61 \%)$ of girls in our survey who regularly played video games enjoyed competition, including $28 \%$ who strongly agreed with this reason for play.

Greenberg et al. (2008) surveyed students of various age groups, ranging from fifth graders to college undergraduates. They found that motivations for game play varied by age or developmental stage. Competition, for example, was more motivating for their samples of eighth and 11th grade students than for the fifth graders (who were more motivated by challenge).

For boys, video games may be a means to jockey for social status, similar to the healthy developmental role filled by "rough and tumble" play (Pellegrini, 2003). Boys can gain status among peers by owning or mastering a popular game. A study of male social identity that included 149 boys $14-15$ years of age (Tarrant et al., 2001) found that "good at computer/video games" was second only to being "fun" as a desirable trait among one's in-group members.

In focus groups with 17 children in Grades 4 to 6 who routinely played video games (Funk, Chan, Brouwer, \& Curtiss, 2006), some also mentioned that competition and the sense of accomplishment and pride that came with winning were key motivators for play. For some, video game skill seemed important to their self-esteem, especially if they had less success in other areas such as academics or sports. The authors quote one child as saying he liked playing video games because "I feel like I actually did something right." But these younger children, who were less experienced and coordinated players, also described frustration with games that were too difficult; this led them to stop playing, at least temporarily.

Multiplayer games can provide a safe space for young people to negotiate rules and discover the boundaries of acceptable behavior-such as the point where creative strategies are viewed as crossing the line into cheating or taking unfair advantage (Barnett \& Coulson, 2010; Chen, 2005; Küchlich, 2008). Similarly, a boy whose avatar throws things at someone else's game character may be engaged in competition, friendly teasing, aggression, or (in the case of throwing at a girl) flirting, depending on the circumstances and type of projectile (Searle \& Kafai, 2009). Younger children 
can practice social give-and-take through activities such as collecting and trading game items (Beals \& Bers, 2009; Bers, 2010).

\section{Youth Teaching Each Other}

Along with friendly competition, boys and girls gain satisfaction from teaching others how to play. In our youth survey, $36 \%$ of boys and $30 \%$ of girls agreed (somewhat or strongly) that teaching others appealed to them. In focus groups, boys described exchanging "cheat codes" and sharing advice on beating a game, for example, "Strategies, like my friend might give me a tip on how to do something, or someone's weakness." Parents of these young gamers made similar observations (Kutner, Olson, Warner, \& Hertzog, 2008). As one father said, "Most of the interaction my son has with his buddies is about solving situations within a game. It's all about how do you go from this place to that place, or collect the certain things that you need, and combine them in ways that are going to help you to succeed."

Peer-based learning can be seen as the positive flip side of the much-maligned "peer pressure" (Ito et al., 2009). In peer-based learning, young people congregate around common interests and motivate one another to learn through a combination of affiliation and competition.

To counterbalance the many experimental laboratory studies in the media effects literature, Stevens, Satwicz, and McCarthy (2008) used ethnographic research methods to intensively study the day-to-day long-term use of video games by a sample of preteens and young adolescents in their natural environments. They noticed patterns of "unprovoked teaching and learning" (p. 52) among peers and siblings, including just-in-time advice on overcoming an obstacle; collaborative learning with shifting teacher-learner roles; and ongoing "apprenticeships" where an older or more experienced player recommends games, informally models how to play, and is available for guidance.

A study of discussion threads (public written conversations) in a multiplayer online game found that (aside from social banter) the majority of content focused on joint problem solving, including knowledge sharing and evidence-based debate (Steinkuehler \& Duncan, 2008). The authors posit that this promotes "scientific habits of mind" and could be an important adjunct to school-based science education.

\section{Making Friends}

Although making new friends was not among the top motivations for video gaming in our survey, video games clearly create common ground that young people can use to make friends. As a boy in one of our focus groups explained, "You can start a conversation by asking, 'Do you own a system, a game system?' If he says 'yes,' then, 'What kind?'” Making friends was a higher ranked motivator, however, for the 78 children we surveyed who were classified as mildly learning disabled. Children in this group were more likely to be victims of bullying and to report being excluded by their peers; thus, they may put a higher value on connecting with peers through video games.

Whether to compete or connect, making friends is a major attraction of online games for adolescents and adults (Przybylski, Rigby, \& Ryan, 2010; Yee, 2006b). The fact that they may never meet in the real world does not diminish the connection felt by online gamers. In his multiyear study of 30,000 players of MMORPGs (massively multiuser online role-playing games, such as Everquest), Yee (2006a) found that among players ages 12 to $17,54.2 \%$ of girls and $30.0 \%$ of boys reported confiding secrets or personal issues to online gaming buddies that they had withheld from real-world friends.

\section{Opportunities to Lead}

In studies of multiplayer online games (Yee, 2006a), many adolescent players felt they had learned leadership skills such as mediation, persuasion, and motivation through their online group play experiences. Online gaming appears to offer a rare opportunity for an adolescent to take multiple roles (including leader) in a diverse, multiage team. As Yee (2006a) notes, "There are very few activities, hobbies or games in real life where you would find people with ages ranging from 11 to 69 interacting and collaborating to achieve shared goals" (p. 324).

\section{Emotional Motivations for Video Game Play}

\section{Regulating Feelings}

Emotions play a surprisingly large role in children's motivations for electronic game use, particularly for boys. In our youth survey, two thirds $(62 \%)$ of boys and $44 \%$ of girls who played electronic games somewhat or strongly agreed that they sometimes used games to help them relax; substantial numbers also used games to cope with anger (45\% of boys and $29 \%$ of girls). Forgetting problems and coping with loneliness were also cited as reasons for play.

Among both boys and girls, those who used games to cope with anger were significantly more likely to play Mature-rated (violent) games (Olson et al., 2007). Using games to work out anger also came up repeatedly in focus groups (Olson et al., 2008), for example, "Getting wrapped up in a violent game, it's good. 'Cause if you mad, when you come home, you can take your anger out on the people in the game." Similarly, in the BBFC focus group studies, both adolescents and adults talked about using video games to "switch off" or "wind down" (Cragg et al., 2007). An interesting finding of Funk and colleagues (2006) was that although college-age youth talked about using games to release stress and anger, mood management did not appear to be a motivator for preteen children.

But video games can do more than purge negative feelings; they can provide fun and stimulation to promote a positive mood. "It's something to do when I'm bored" was one of the most frequently cited motivations for play in our youth survey, by both boys and girls.

\section{Video Games and Flow}

Several studies have been published on video games and flow: a state of being pleasantly and completely absorbed by a goal-driven activity. Matching the level and tempo of challenge to a player's skills increases the likelihood of achieving flow (Annetta, 2010; Kiili, 2005; Sherry, 2004). The concept of flow may also explain why children prefer certain types of video games or choose to give up on a game. Sherry (2004) posits that certain visual-spatial skills 
(e.g., targeting, spatial rotation), which are typically less developed in girls, may prevent girls from easily achieving flow at the beginner levels of popular action games such as Quake. Games that lack a series of structured challenges, such as games involving virtual dolls, are not conducive to flow (Inal \& Cagiltay, 2007).

\section{Intellectual and Expressive Motivations}

\section{Challenge and Mastery}

Compared with other entertainment media (TV, radio, books), video game play demands a wider range of skills as well as a high tolerance for frustration. Specialized knowledge is required to install and use the game on the console or computer and to master the ever-evolving game controllers or game-specific keyboard commands. With each new game or game series, the player must figure out that game world's regulatory mechanisms and causal connections before any fun can be had (Klimmt \& Hartmann, 2006).

When we asked boys in focus groups what made a video game fun to play more than once, challenge was a key factor. An easy game that does not require much time or focus to beat is not as much fun. Games with multiple storylines are appealing because after finishing one storyline, a player can "beat it again" (Olson et al., 2008).

Challenge was also cited by participants in the BBFC study (Cragg et al., 2007). Some favorably compared video games with $\mathrm{TV}$, for example, "It's like watching TV but there is a sense of achievement" (p. 39). In a principal components analysis of survey data from online game players (Yee, 2006b), "achievement" was one of the three primary components identified. The achievement category included "advancement," the motivation to progress through the game and gain power and status symbols; "mechanics," figuring out the game's system and underlying rules to promote that advancement; and "competition," which includes challenging other players.

Joseph (2009) gives an example of how a 12-year-old player of Grand Theft Auto found and exploited flaws in the game's structure. The boy's preferred play mode was driving a taxi around town. He learned that a quick way to find passengers was to run over pedestrians and wait for them to get up; they would then climb into his cab.

\section{Expressing Creativity}

A growing number of electronic games provide tools that allow players to create new content. "Modding" can range from simple customization of game characters' appearance to the creation of new game levels. More challenging types of modding require a deep understanding of game rules and structure. A national telephone survey of youth ages 12 to 17 for the Pew Internet \& American Life Project found that $36 \%$ of boys and $20 \%$ of girls who play video games often or sometimes used mods to change their games (Lenhart et al., 2008).

Open-ended games with multiple solutions and play options, sometimes called sandbox games, are especially conducive to modding and self-expression. Squire (2008) refers to such games as "possibility spaces," where multiple trajectories of experience can lead to new ways of learning. Examples of sandbox games include simulation games (such as Sim City or Rollercoaster Tycoon) as well as less obvious ones such as the Grand Theft Auto series, where players can follow a flexible storyline or pursue a range of activities.

Stevens et al. (2008) observed children customizing games in ways that highlighted their distinct personalities and interests. For example, one girl playing Zoo Tycoon focuses on efficiently beating levels and maximizing the functionality of her zoo, whereas another girl is absorbed by design principles and beautification. Even young children with limited fine motor skills can express their creativity (and gain self-esteem) in a well-designed game or virtual play space (Beals \& Bers, 2009).

\section{Experimentation With Different Identities}

Customizing game characters can also be one way to experiment with different identities. In virtual worlds and multiplayer online games, children can design characters that look like them or they can try out looks that represent different ideas about masculinity and femininity. They can also enjoy the transgressive role of a scammer or bad guy or girl without real-life consequences while keeping their offline self-image as a good person (Kafai, Fields, \& Giang, 2009; Searle \& Kafai, 2009).

Children also enjoy the chance to experience being powerful or famous through a game character. These fantasies were reflected in the responses of boys in our focus groups when we asked what they would do if they could be a favorite game character for a day, for example, "If I were Sub-Zero, I would go to school, I would freeze my teacher and the principal, and all the other teachers. So the students could do whatever they want. They could run in the hallways!" Research on college students also suggests that identification with an appealing protagonist makes a game more fun (Hefner, Klimmt, \& Vorderer, 2007). Video games with skilled protagonists allow players to temporarily perceive themselves as experts, possessing the special powers of a cunning criminal or a skilled warrior (Gee, 2007).

An increasing number of games feature strong playable female characters (or the option to play as either a male or female). Opinions differ on whether hypersexualized female characters (such as Lara Croft in the Tomb Raider series) deter women from playing, or whether (regardless of her appearance) a powerful female character might attract women (Jansz \& Martis, 2007).

\section{Curiosity, Discovery, and Learning}

The fun of "unreality." Doing things you cannot do in real life (and often would recoil from in reality) can be part of the appeal of games. In our focus groups, after noting that he enjoyed both gory games and fantasy games, one boy said, "I just love the fact that I know it can't happen. I just love all the things that they can do. 'Cause if you're in a real world, then there's limitations to what you can do and what you can't do." Adolescents in the BBFC focus groups by Cragg et al. (2007) also spoke about the "fun of knowing you can do these things in a game, but obviously you can't in real life" (p. 37). The game takes you away from reality and responsibility, "and it doesn't matter if you crash" (p. 38).

In group interviews, high school-age Grand Theft Auto: San Andreas fans from poor neighborhoods felt that game violence was not realistic when judged against the real-life violence they had 
observed or experienced (Squire, 2008). In contrast, they found the game's references to popular culture, such as hip-hop music and fashion, to be enjoyably realistic.

Although some associate realism with sophisticated graphics, "realistic" turns out to be a complex concept. When Malliet (2006) conducted structured interviews with 32 adolescent gamers, graphic realism was just one of five dimensions of perceived realism. Another dimension was "factuality," or incorporating facts-historical events, geographic locations, training procedures, weapons, or outcomes of actions-which made games seem more real. "Authenticity" has to do with well-developed characters whose emotions or actions feel real, even if they are not actually plausible or likely. Another element is a sense of virtual experience, which can be increased by more freedom to choose courses of action or allowing a game character to evolve based on player behavior. A final factor is involvement or identification with game characters, which may be affected by the player's ability to shape the story or customize a character or by a first-person perspective (perceiving game action as if through the character's eyes).

Incorporating a story allows a game to be more complex because the story can integrate a set of challenges into a larger problem (Kiili, 2005). From an educator's perspective, increased immersion in a game through identification with a character, and discovering events through that character's experiences, may increase factual learning and introspection concerning moral dilemmas (Jenkins, Clinton, Purushotma, Robison, \& Weigel, 2006). Gee (2009) points to recent research showing the role of emotion in learning, and suggests that video games help motivate learning by linking emotions to problem solving.

Discovering and feeding interests. More than half of the children in our survey agreed that they liked to learn new things from video games; nearly one child in five was strongly motivated to play by the chance to learn. Shaffer and Gee (2005) give the example of a child whose interest in mythology (and related topics such as cultures, geography, and history) is stoked by playing Age of Mythology. The ability to "mod" this game through designing and exchanging maps and scenarios with other players adds to the appeal (and to the acquisition of technical skills). The game also creates a "hook" parents can use to connect their child to related material in books, on the Web, and in museums.

In our youth survey, $73.6 \%$ of boys and $46.7 \%$ of girls included at least one realistic sports game (e.g., skateboarding, dancing, basketball) on their list of five frequently played games. Greater realism may make sports games especially attractive and inspiring. As one boy said in a focus group, "In the games that are real, which are mostly the sports games, you see them do amazing plays. And then if you were to go outside and try them, and keep practicing that, you could get better so you can, sometime later on in life, you could probably, possibly do that." Dance games seem particularly appealing to girls and meet a powerful combination of needs, including fun, exercise, socializing, competing, and showing off skills (Lieberman, 2006).

\section{The Appeal of Violent or Mature Content}

In our youth survey sample, the most popular game series among boys and one of the most popular among girls was Grand Theft Auto (Olson et al., 2007). Although there are no acts of violence against children or animals (both are absent from the game world), this sandbox game allows the player tremendous freedom to commit mayhem. The wide exposure of young adolescents to this Mature-rated (age 17+) game worries many adults. They are concerned that playing a thug in a video game may amount to rehearsal for real-life thuggery. But a deeper exploration of the appeal of violent content suggests that it may be more complex and less deviant than parents fear.

\section{The Specific Appeal of Violent Video Games}

We found that boys and girls who regularly played at least one Mature-rated game title were significantly more likely to endorse four reasons for play: to compete and win, to get anger out, liking to "mod" games, and liking "the guns and other weapons" (Olson et al., 2007). As noted earlier, our focus group studies (and those of others) found that violent games were often used to vent anger and relieve stress.

Violent content can serve to enhance the emotional appeal of a game. This may come from "artifact emotions" (reflecting aesthetic appreciation for beautifully rendered or creative graphics) or from "representative emotions" (feelings that arise from immersion in and engagement with the game world, as when one's game character achieves a goal or is thwarted; Tan, 2000). The enjoyment of "the guns and other weapons" in our study could reflect the challenge of figuring out and mastering novel weapons, the excitement of colorful explosions, or appreciation of new and creative ways to blast zombies and aliens to oblivion.

Compared with real life or a movie, a video game allows players more control over emotions; players can choose situations to elicit or avoid particular feelings (Cragg et al., 2007). Teens who use games to experiment with different identities may be drawn to violent games to, for example, act out an extreme version of powerful masculinity safe from the judgment of parents or society, and to see how it feels (Jansz, 2005).

\section{Is It Really About the Violence?}

Przybylski, Ryan, and Rigby (2009) conducted a series of survey and experimental studies involving young adult online game players and college undergraduates to look at the potential motivating value of violent content in context with other motivations for play. They found that when games provided opportunities for competence and mastery and meaningful choices and options (autonomy), violent content added little unique variance to enjoyment, value, or desire for future play. Thus, nonviolent games that also offer desirable options and challenges might be equivalent in appeal. The authors did find that high trait aggression played a minor role in greater preference for and valuation of violent games (see also Markey \& Markey, 2010), but not in game enjoyment.

Our focus groups with young adolescent boys echoed these findings. When we asked preteen boys whether violence makes a video game more fun, some agreed that they enjoyed games featuring over-the-top violence "that you can't do in real life." But some also noted that violent games were more likely to include action, challenge, and options (Olson et al., 2008). It is interesting that multiple regression analyses of our survey data from seventh and eighth grade youth did not find a relationship between trait anger or aggressive personality and greater use of Mature-rated games (Olson et al., 2009). 
An unexpected theme that arose in several of our focus groups was a feeling among boys that violent games can teach moral lessons. With the Mature-rated Grand Theft Auto: Vice City, for example, "It depends on how you look at it," one boy stated. "If you look at it for fun, it really doesn't teach you anything. But if you look at it as [Sonny's] life story, as the guy's point of view, you go through a lot of changes. And you have to kill people to get where you're at. And the end of the game, you stop killing people because you don't want to be in that situation no more. Because, once you're in a gang, you really can't get out."

\section{Violent Video Games in the Context of Normal Development}

Historically, boys and men have been particularly drawn to group experiences of vicarious violence, from war games to horror films to boxing or wrestling matches (see Ferguson, 2010). Goldstein (1999) suggests that shared consumption of violent entertainment is a bonding opportunity for males and a chance to convey one's masculine identity to peers.

Boys in particular often use rough-and-tumble play fighting to establish dominance and a social pecking order, with no intention to harm (Pellegrini, 2003). Video game play could serve as another arena for the developmentally appropriate battle for status among peers. Given that boys employ play fighting in their tentative moves toward relationships with girls (Pellegrini, 2003), video games might also have a role in promoting healthy boy-girl friendships.

An attraction to violent and scary themes seems to be part of normal development. Playing with those frightening images helps a child master the physical and emotional sensations that go with being afraid. Historically, that was an important and even lifesaving skill. Scary stories and games let children experience and deal with those feelings at a time and place where they know they are safe. That is why fairy tales often dealt with themes like abandonment, murder, even cannibalism, and other content we now think of as "adult."

Fairy tales also offer a glimpse of adult secrets, the things we talk about behind closed doors. One mother in our focus groups, when asked what might attract her son to violent games, said, "I think he would say that he wants to see the blood and guts .... It's something that in his world you don't see in real life. If the dragon gets his head cut off, he wants to know, is the blood red? Is it blue? Is it green?" (Kutner et al., 2008). One could argue that a violent game series such as Grand Theft Auto fits into a tradition of stories that deal with violence, rage, primal fears, and sexuality.

A review of the history of parents' attitudes toward fear (gleaned from a century's worth of parenting advice manuals and children's literature) shows a pronounced shift in social norms (Stearns \& Haggerty, 1991). Victorian-era parents acknowledged that children would inevitably confront fear-inducing situations; the prevailing view was that learning to face or even master fear could improve character. "Good" modern parents are supposed to limit their children's exposure to "negative" emotions, including fear, rather than celebrating their ability to cope with and overcome fear.

A study by Cortez and Bugental (1995) points to potential benefits of mastering fear through use of frightening media content. A sample of 5- and 6-year-old children watched a short videotaped fairy tale (narration with pictures) with either a child narrator and a plot where children saved parents from doom or an adult narrator and a story about a mother rescuing her children from evil. Children then watched a short video about a child's routine visit to a doctor. The authors found that children who were "primed" with the story of child control were buffered from stress and more able to take in new information.

In a study of girls in Grades 6 to 8 attending a game design program (Denner, Bean, \& Werner, 2005), the primary theme in the 45 finished games they created was expressing and working through fears. These included fears of getting into trouble, potential violence, damage to relationships, and failing in school.

In a review of research on enjoyment of frightening or violent media content, Hoffner and Levine (2005) found that people scoring higher on measures of sensation seeking or aggressiveness and lower on measures of empathy were more attracted to such media. This group was disproportionately male. However, the study sample included only films and TV programs.

More studies are needed to understand whether scary or violent interactive media might have different attractions or attract different types of people than passive media. For example, Cragg et al. (2007) speculate that video game violence is unlikely to be shocking in the way film violence can be given that the player has control over it. Informal discussions with young adult game players suggest that some use survival and horror games to process fear, playing the game over and over (from different character perspectives, as the game allows) until the frightening content has been mastered.

\section{Discussions and Implications}

Compared with other media such as books, films, and radio, electronic games appear to have an unusually expansive appeal and serve a surprising number of emotional, social, and intellectual needs. They are also an increasingly complex and varied medium, available in an expanding range of formats and places. As Stevens et al. (2009) note, we can no longer think simplistically about what makes video games motivating, with the goal of capturing that special ingredient and deploying it for more serious pedagogical purposes. Young people's personal traits and the settings (social and physical) in which they play video games all strongly influence how they choose to interact with those games and how those game experiences may influence the adults they become.

Developmental stage and cognitive development also influence the types of games children find attractive. For example, children under 10 are less able to process plot features, and may become more interested in and able to follow complex storylines as preteens or teens (Greenberg et al., 2008). This is why a 10-year-old may view and interact with Grand Theft Auto as simply a driving game.

Steinberg's (2008) review of neuroscience research on why risk taking and sensation seeking increase in early adolescence suggests that it is a normal biologically driven behavior. He concludes that our best bet may be to focus on "limiting opportunities for immature judgment to have harmful consequences (p. 99)." One might argue that video games are a safer outlet for these drives than experimenting with drugs or alcohol or fast and reckless driving. (This article does not address how violent or frightening video games might affect children with serious behavioral or 
emotional problems or developmental delays; there are virtually no data on this. See Savage, 2008, or Ferguson, 2010, for a review of what is known about media violence and real-world violence.)

To minimize potential harm, parents might focus on "video game literacy" (Klimmt, 2009) and limit unsupervised play. Like other media, video games can promote harmful stereotypes (e.g., game characters identified as Arabic are often terrorists; many female characters have unrealistic body proportions). Research on efforts to mediate (and mitigate any harmful effects of) children's viewing of violent TV programs shows that as children approach adolescence, stating judgments about content (such as its factual reality or social appropriateness) can backfire and make violent content more appealing (Nathanson \& Yang, 2003). Asking questions about the child's views to promote critical thinking (without requiring the child to answer out loud) was a more effective approach.

Our research suggests that game consoles and computers in children's bedrooms increase the odds that they will spend more time with electronic games in general and games with violent content in particular (Olson et al., 2008). Routinely keeping game systems in common areas of the home allows parents to set sensible limits on play time and to monitor for negative effects such as increased anger, irritability, or aggression.

In our survey of seventh and eighth graders, $54.8 \%$ reported that they never played electronic games with a parent, and another $23.9 \%$ rarely did so. These data were collected in late 2004, so it is likely (with the advent of more family-friendly game systems such as the Nintendo Wii) that more parents and children play together today, as suggested by industry surveys (Ito et al., 2008). Asking your child to teach you to play a video gamereversing the usual parent-child role-may be good for parentchild relationships (Villani, Olson, \& Jellinek, 2005). It also implies respect for the child's interests and skill in a culture that often dismisses video games as a waste of time.

\section{References}

Annetta, L. (2010). The "I's" have it: A framework for serious educational game design. Review of General Psychology, 14, 105-112.

Barnett, J., \& Coulson, M. (2010). Virtually real: A psychological perspective on massively multiplayer online games. Review of General Psychology, 14, 167-179.

Beals, L., \& Bers, M. U. (2009). A developmental lens for designing virtual worlds for children and youth. International Journal of Learning and Media, 1, 51-65.

Bers, M. U. (2010). Let the games begin: Civic playing in high-tech consoles. Review of General Psychology, 14, 147-153.

Chen, M. (2005, June). Addressing social dilemmas and fostering cooperation through computer games. Paper presented at the DIGRA 2005 Conference. Retrieved from http://www.digra.org/dl/db/06278.44316 .pdf

Cortez, V. L., \& Bugental, D. B. (1995). Priming of perceived control in young children as a buffer against fear-inducing events. Child Development, 66, 687-696.

Cragg, A., Taylor, C., \& Toombs, B. (2007). Video games: Research to improve understanding of what players enjoy about video games, and to explain their preferences for particular games. London: British Board of Film Classification. Retrieved from http://www.bbfc.co.uk

Denner, J., Bean, S., \& Werner, L. (2005, June). Girls creating games: Challenging existing assumptions about game content. Paper presented at the DIGRA 2005 Conference. Retrieved from http://www.digra.org/ $\mathrm{dl} / \mathrm{db} / 06278.43275 . \mathrm{pdf}$

Ferguson, C. J. (2010). Blazing angels or resident evil? Can violent video games be a force for good? Review of General Psychology, 14, 68-81.

Funk, J. B., Chan, M., Brouwer, J., \& Curtiss, K. (2006). A biopsychosocial analysis of the video game-playing experience of children and adults in the United States. SIMILE: Studies in Media \& Information Literacy Education, 6(3), 79. Retrieved from http://www.utpjournals.com/simile/ issue23/Funk1.html

Gee, J. P. (2007). Pleasure, learning, video games, and life: The projective stance. In M. Knobel \& C. Lankshear (Eds.), A new literacies sampler (pp. 95-113). New York: Peter Lang.

Gee, J. P. (2009). Learning and games. International Journal of Learning and Media, 1, 21-40.

Goldstein, J. (1999). The attractions of violent entertainment. Media Psychology, 1, 271-282.

Greenberg, B. S., Sherry, J., Lachlan, K., Lucas, K., \& Holmstrom, A. (2008). Orientations to video games among gender and age groups. Simulation \& Gaming. Advance online publication. doi:10.1177/ 1046878108319930

Hefner, D., Klimmt, C., \& Vorderer, P. (2007). Identification with the player character as determinant of video game enjoyment. In L. Ma, M. Rauterberg, \& R. Nakatsu (Eds.), Entertainment computingInternational Conference of Entertainment Computing (pp. 39-48). Berlin: Springer.

Hoffner, C. A., \& Levine, K. J. (2005). Enjoyment of mediated fright and violence: A meta-analysis. Media Psychology, 7, 207-237.

Inal, Y., \& Cagiltay, K. (2007). Flow experiences of children in an interactive social game environment. British Journal of Educational Technology, 38, 455-464.

Ito, M., Baumer, S., Bittani, M., Boyd, D., Cody, R., Herr, B., .. . Tripp, L. (2009). Introduction. In Hanging out, messing around, geeking out: Living and learning with new media (pp. 1-28). Cambridge, MA: MIT Press.

Ito, M., \& Bittani, M. (2009). Gaming. In M. Ito, S. Baumer, M. Bittani, et al. (Eds.), Hanging out, messing around, geeking out: Living and learning with new media (pp. 195-242). Cambridge, MA: MIT Press.

Ito, M., Horst, H., Bittanti, M., Boyd, D., Herr-Stephenson, B., Lange, P. G., ... Robinson, L. (2008). Living and learning with new media: Summary of findings from the Digital Youth Project. John D. \& Catherine T. MacArthur Foundation Reports on Digital Media and Learning. Retrieved from http://www.macfound.org

Jansz, J. (2005). The emotional appeal of violent video games for adolescent males. Communication Theory, 15, 219-241.

Jansz, J., \& Martis, R. G. (2007). The Lara phenomenon: Powerful female characters in video games. Sex Roles, 56, 141-148.

Jenkins, H., Clinton, K., Purushotma, R., Robison, A. J., \& Weigel, M. (2006). Confronting the challenges of participatory culture: Media education for the 21st century. Chicago: MacArthur Foundation.

Joseph, B. (2009). Why Johnny can't fly: Treating games as a form of youth media within a youth development framework. International Journal of Learning and Media, 1, 253-266.

Kafai, Y. B., Fields, D., \& Giang, M. T. (2009). Transgressive gender play: Profiles and portraits of girl players in a tween virtual world. In Breaking new ground: Innovation in games, play, practice and theory. Paper presented at the DIGRA 2009 Conference. Retrived from http:// www.digra.org/dl/order_by_author?publication $=$ Breaking $\% 20 \mathrm{New} \% 20$ Ground:\%20Innovation\%20in\%20Games,\%20Play,\%20Practice $\% 20$ and\%20Theory. London: DIGRA.

Kiili, K. (2005). Digital game-based learning: Toward an experiential gaming model. Internet and Higher Education, 8, 13-24.

Klimmt, C. (2009). Key dimensions of contemporary video game literacy: Towards a normative model of the competent digital gamer. Eludamos: Journal for Computer Game Culture, 3, 23-31. 
Klimmt, C., \& Hartmann, T. (2006). Effectance, self-efficacy, and the motivation to play video games. In P. Vorderer \& J. Bryant (Eds.), Playing video games: Motives, responses and consequences (pp. 133146). Hillsdale, NJ: Erlbaum.

Küchlich, J. (2008). Forbidden pleasures: Cheating in computer games. In M. Swalwell \& J. Wilson (Eds.), The pleasures of computer gaming (pp. 52-71). Jefferson, NC: McFarland.

Kutner, L. A., Olson, C. K., Warner, D. E., \& Hertzog, S. M. (2008). Parents' and sons' perspectives on video game play: A qualitative study. Journal of Adolescent Research, 23, 76-96.

Lenhart, A., Kahne, J., Middaugh, E., Macgill, A. R., Evans, C., \& Vitak, J. (2008). Teens, video games, and civics. Pew Internet \& American Life Project. Retrieved from http://www.pewinternet.org

Lieberman, D. A. (2006). Dance games and other exergames: What the research says. Retrieved from http://www.comm.ucsb.edu/faculty/ lieberman/exergames.htm

Malliet, S. (2006). An exploration of adolescents' perceptions of videogame realism. Learning, Media and Technology, 31, 377-394.

Markey, P. M., \& Markey, C. N. (2010). Vulnerability to violent video games: A review and integration of personality research. Review of General Psychology, 14, 82-91.

Nathanson, A. I., \& Yang, M. S. (2003). The effects of mediation content and form on children's responses to violent television. Нитап Соттиnication Research, 29, 111-134.

Olson, C. K., Kutner, L. A., Baer, L., Beresin, E. V., Warner, D. E., \& Nicholi, A. M., II. (2009). M-rated video games and aggressive or problem behavior among young adolescents. Applied Developmental Science, 13(4), 188-198.

Olson, C. K., Kutner, L. A., \& Warner, D. E. (2008). The role of violent video game content in adolescent development: Boys' perspectives. Journal of Adolescent Research, 23, 55-75.

Olson, C. K., Kutner, L. A., Warner, D. E., Almerigi, J. B., Baer, L., Nicholi, A. M., II, \& Beresin, E. V. (2007). Factors correlated with violent video game use by adolescent boys and girls. Journal of Adolescent Health, 41, 77-83.

Pellegrini, A. D. (2003). Perceptions and functions of play and real fighting in early adolescence. Child Development, 74, 1522-1533.

Przybylski, A. K., Rigby, C. S., \& Ryan, R. M. (2010). A motivational model of videogame engagement. Review of General Psychology, 14, 154-166.

Przybylski, A. K., Ryan, R. M., \& Rigby, C. S. (2009). The motivating role of violence in video games. Personality and Social Psychology Bulletin, 35, 243-259.

Roberts, D. F., Foehr, U. G., \& Rideout, V. (2005). Generation M: Media in the lives of 8-18 year-olds. Menlo Park, CA: Kaiser Family Foundation.

Savage, J. (2008). The role of exposure to media violence in the etiology of violent behavior: A criminologist weighs in. American Behavioral Scientist, 51, 1123-1136.
Searle, K. A., \& Kafai, Y. B. (2009). Boys' play in the fourth space: Freedom of movements in a tween virtual world. In Breaking new ground: Innovation in games, play, practice and theory. Paper presented at the DIGRA 2009 Conference. Retrived from http://www.digra.org/dl/ order_by_author?publication $=$ Breaking $\% 20 \mathrm{New} \% 20 \mathrm{Ground}: \% 20$ Innovation\%20in\%20Games, \%20Play,\%20Practice\%20and\%20Theory. London: DIGRA.

Shaffer, D. W., \& Gee, J. P. (2005). Before every child is left behind: How epistemic games can solve the coming crisis in education. Wisconsin Center for Education Research Working Paper No. 2005-7. Retrieved from http://www.wcer.wisc.edu/publications/workingPapers/index.php

Sherry, J. L. (2004). Flow and media enjoyment. Communication Theory, $14,328-347$.

Squire, K. (2008). Open-ended video games: A model for developing learning for the interactive age. In K. Salen (Ed.), The ecology of games: Connecting youth, games, and learning (pp. 167-198). Cambridge, MA: MIT Press.

Stearns, P. N., \& Haggerty, T. (1991). The role of fear: Transitions in American emotional standards for children, 1850-1950. American Historical Review, 96, 63-94.

Steinberg, L. (2008). A social neuroscience perspective on adolescent risk-taking. Developmental Review, 28, 78-106.

Steinkuehler, C., \& Duncan, S. (2008). Scientific habits of mind in virtual worlds. Journal of Science Education and Technology, 17, 1573-1839.

Stevens, R., Satwicz, T., \& McCarthy, L. (2008). In-game, in-room, in-world: Reconnecting video game play to the rest of kids' lives. International Journal of Learning and Media, 1(1), 41-66.

Tan, E. S. (2000). Emotion, art, and the humanities. In M. Lewis \& J. M. Haviland-Jones (Eds.), Handbook of emotions (2nd ed., pp. 116-135). New York: Guilford Press.

Tarrant, M., North, A. C., Edridge, M. D., Kirk, L. E., Smith, E. A., \& Turner, R. E. (2001). Social identity in adolescence. Journal of Adolescence, 24, 597-609.

Villani, V. S., Olson, C. K., \& Jellinek, M. S. (2005). Media literacy for clinicians and parents. Child and Adolescent Psychiatric Clinics of North America, 14, 523-553.

von Salisch, M., Oppl, C., \& Kristen, A. (2006). What attracts children? In P. Vorderer \& J. Bryant (Eds.), Playing video games: Motives, responses and consequences (pp. 147-163). Hillsdale, NJ: Erlbaum.

Yee, N. (2006a). The demographics, motivations and derived experiences of users of massively multi-user online graphical environments. Presence: Teleoperators and Virtual Environments, 15, 309-329.

Yee, N. (2006b). Motivations for play in online games. CyberPsychology \& Behavior, 9, 772-775.

Received December 28, 2009 Revision received December 28, 2009 Accepted January 16, 2010 